\title{
Measurements of Breakdown Field and Forward Current Stability in 3C-SiC pn Junction Diodes Grown on Step-Free 4H-SiC
}

\author{
Philip G. Neudeck ${ }^{1, a}$, David J. Spry ${ }^{2, b}$ and Andrew J. Trunek ${ }^{2, c}$ \\ ${ }^{1}$ NASA Glenn Research Center, MS 77-1, 21000 Brookpark Road, Cleveland, OH 44135 USA \\ ${ }^{2} \mathrm{OAI}$ at NASA Glenn Research Center, MS 77-1, 21000 Brookpark Road, Cleveland, OH 44135 \\ USA \\ âNeudeck@nasa.gov, 'David.J.Spry@grc.nasa.gov, 'Andrew.J.Trunek@grc.nasa.gov
}

Keywords: $3 \mathrm{C}-\mathrm{SiC}$, pn junction, $\mathrm{p}^{+} \mathrm{n}$ diode, rectifier, reverse breakdown, breakdown field, heteroepitaxy, epitaxial growth, electroluminescence, mesa, bipolar diode

\begin{abstract}
This paper reports on initial fabrication and electrical characterization of $3 \mathrm{C}-\mathrm{SiC} \mathrm{p}^{+} \mathrm{n}$ junction diodes grown on step-free $4 \mathrm{H}-\mathrm{SiC}$ mesas. Diodes with n-blocking-layer doping ranging from $\sim 2 \times 10^{16} \mathrm{~cm}^{-3}$ to $\sim 5 \times 10^{17} \mathrm{~cm}^{-3}$ were fabricated and tested. No optimization of junction edge termination or ohmic contacts was employed. Room temperature reverse characteristics of the best devices show excellent low-leakage behavior, below previous $3 \mathrm{C}-\mathrm{SiC}$ devices produced by other growth techniques, until the onset of a sharp breakdown knee. The resulting estimated breakdown field of $3 \mathrm{C}-\mathrm{SiC}$ is at least twice the breakdown field of silicon, but is only around half the breakdown field of $<0001>4 \mathrm{H}-\mathrm{SiC}$ for the doping range studied. Initial high current stressing of $3 \mathrm{C}$ diodes at $100 \mathrm{~A} / \mathrm{cm}^{2}$ for more than 20 hours resulted in less than $50 \mathrm{mV}$ change in $\sim 3 \mathrm{~V}$ forward voltage.
\end{abstract}

\section{Introduction}

Recent advancements in cubic-SiC crystal growth and MOSFET properties have renewed interest in the $3 \mathrm{C}$ polytype for realizing beneficial high power and/or high temperature electronics [1-3]. Until recently, 3C-SiC extended defect densities were too high to support fabrication of even small-area $3 \mathrm{C}-\mathrm{SiC}$ devices free of dislocations. Step-free surface heteroepitaxy has enabled dislocation-free layers of $3 \mathrm{C}-\mathrm{SiC}$ to be realized on top of small device-sized mesas arrayed across on-axis $4 \mathrm{H}-\mathrm{SiC}$ wafers [3]. This paper reports on fabrication and electrical characterization of breakdown field and forward bias current stability of an initial lot of small-area epitaxial $3 \mathrm{C}-\mathrm{SiC} \mathrm{p}^{+} \mathrm{n}$ junction diodes grown on step-free $4 \mathrm{H}-\mathrm{SiC}$ mesas.

\section{Experimental}

Fig. 1 shows a simplified schematic cross-section of the $\mathrm{p}^{+} \mathrm{n}$ junction diodes that were studied. The buried $3 \mathrm{C} / 4 \mathrm{H}$ heterojunction was grown with heavy n-type doping in order to minimize its impact on top contact to backside contact (Fig. 1b) electrical measurements. The diodes were fabricated starting from a quarter of a commercially purchased on-axis $4 \mathrm{H}-\mathrm{SiC}$ wafer [4]. Except as noted below, the epitaxial growth processes employed, namely step free surface heteroepitaxy [3] and site-competition doping [5], have been previously described. Patterned etching of trenches to a depth of $\sim 10 \mu \mathrm{m}$ to form pre-growth mesas arrayed across the wafer was carried out by the wafer vendor [4]. The wafer was piranha cleaned and loaded into a modified horizontal-flow single-wafer cold-wall chemical vapor deposition system with an inductively heated stationary (no rotation) uncoated graphite susceptor [6]. An in-situ pre-growth etch was performed at $\sim 1200{ }^{\circ} \mathrm{C}$ with 120 $\mathrm{sccm} \mathrm{HCl}$ diluted in $4 \mathrm{slm}$ of $\mathrm{H}_{2}[3,7]$. The substrate temperature was then ramped over 5 minutes to $\sim 1500{ }^{\circ} \mathrm{C}$ and step-flow growth carried out by flowing $6.7 \mathrm{sccm} \mathrm{N} \mathrm{N}_{2}, 2.7 \mathrm{sccm} \mathrm{SiH}_{4}$ and $3 \mathrm{sccm}$ $\mathrm{C}_{3} \mathrm{H}_{8}(\mathrm{Si} / \mathrm{C}$ ratio of 0.9$)$. For mesas not threaded by substrate screw dislocations, this step produces 


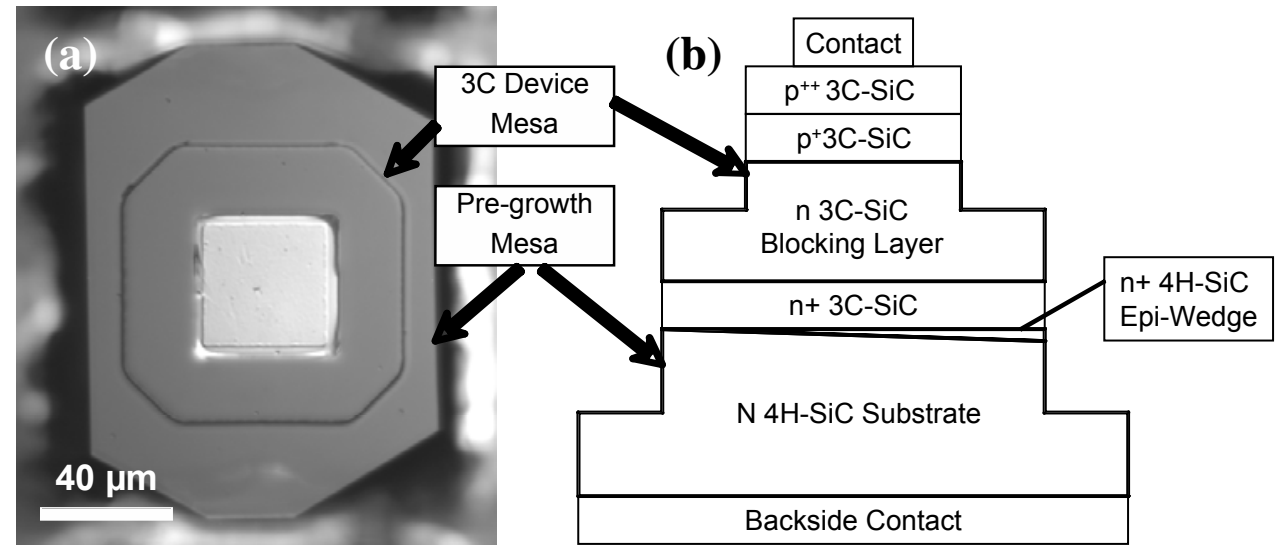

Fig. 1. (a) Optical microscope photo top view and (b) simplified schematic cross-sectional depiction of $3 \mathrm{C}-\mathrm{SiC} \mathrm{p}^{+} \mathrm{n}$ junction diode structure grown on top of step-free $4 \mathrm{H}-\mathrm{SiC}$ mesa studied in this work. For simplicity, SiC deposition on pre-growth mesa sidewalls is not shown in (b). a heavily doped $\mathrm{n}^{+}$ 4H-SiC epi-wedge with atomically flat top surface (Fig. 1) [3]. The substrate temperature was then lowered to $\sim 1380{ }^{\circ} \mathrm{C}$ over 10 minutes to ensure nucleation of high quality $3 \mathrm{C}-\mathrm{SiC}$ heteroepilayer [3], and then increased to $\sim 1410 \quad{ }^{\circ} \mathrm{C}$ over 2 minutes where it remained for the rest of the $3 \mathrm{C}-\mathrm{SiC}$ layer growth. The $\mathrm{n}^{+} 3 \mathrm{C}$-SiC layer was grown for 15 minutes at these conditions, followed by 3 hours of lighter-doped n 3C-SiC blocking layer growth under reduced $\mathrm{N}_{2}$ flow of $0.25 \mathrm{sccm}$. The $\mathrm{p}^{+}$layer was then grown by eliminating the $\mathrm{N}_{2}$, reducing the $\mathrm{SiH}_{4}$ to $1.5 \mathrm{sccm}$ ( $\mathrm{Si} / \mathrm{C}$ ratio of 0.5 ), and adding $0.5 \mathrm{sccm}$ trimethylaluminum (TMAl) for 15 minutes [5]. Process test films grown in these conditions yielded $\sim 10^{18} \mathrm{~cm}^{-3}$ p-type and growth rates near $1.2 \mu \mathrm{m} /$ hour. An even heavier-doped $\mathrm{p}^{++}$ $3 \mathrm{C}$-SiC layer $\left(>10^{19} \mathrm{~cm}^{-3}\right)$ to assist p-type ohmic contact formation was then grown for 30 minutes by increasing the TMAl to $4 \mathrm{sccm}$ 's. In the final minute of growth, the $\mathrm{SiH}_{4}$ flow was cutoff to promote surface Al dopant saturation [5].

Following growth the quarter-wafer piece was surveyed by differential interference contrast (DIC) optical microscopy to verify formation of at least a few mesas with lateral cantilevers and smooth double-positioning boundary (DPB) free surface morphology expected for high-quality 3C$\mathrm{SiC}$ mesa heterofilms [3]. Unfortunately, the particular $4 \mathrm{H}-\mathrm{SiC}$ commercial substrate used for this initial experiment suffered from unusually high axial screw dislocation density (well over $2 \times 10^{4}$ $\mathrm{cm}^{-2}$ ), so that only a little more than a dozen out of $\sim 300$ of the smallest pre-growth mesas with diodes on them yielded the expected good $3 \mathrm{C}-\mathrm{SiC}$ film morphology.

In order to fully isolate the $3 \mathrm{C}^{+} \mathrm{n}$ junction, a Ti/Ni metal etch mask was patterned and the mesa epilayers were reactive ion etched to a depth of $\sim 3 \mu \mathrm{m}$ in a fluorine plasma. The etch mask was then stripped and the sample piranha cleaned prior to depositing $\mathrm{Ti} / \mathrm{TaSi}_{2} / \mathrm{Pt}$ as a backside metal contact [8]. Prior to topside ohmic contact deposition, the quarter wafer was sawed in half and one piece was set aside. Thin Al/Ti/Al $(5 \mathrm{~nm} / 10 \mathrm{~nm} / 10 \mathrm{~nm})$ layers were electron beam deposited at $7 \mathrm{x}$ $10^{-8}$ Torr, patterned via wet etching, and annealed in a tube furnace at $800{ }^{\circ} \mathrm{C}$ for 30 minutes in an Ar atmosphere. Ti/Ni $(25 \mathrm{~nm} / 200 \mathrm{~nm})$ was then deposited and patterned by lift-off on top of the thin annealed $\mathrm{Al} / \mathrm{Ti} / \mathrm{Al}$ to finish the p-type top diode contact. No optimization of junction edge termination or ohmic contacts was employed.

Electrical results summarized in this paper were recorded from six high-quality small-area $(\mathrm{A}=$ $5.9 \times 10^{-5} \mathrm{~cm}^{2}$ ) $3 \mathrm{C}$ diodes that were not threaded by the high density of underlying $4 \mathrm{H}-\mathrm{SiC}$ substrate screw dislocations. Electrical characterization was carried out in near-dark conditions at room temperature on a probing station using computer-controlled source-measure units and $1 \mathrm{MHz}$ capacitance bridge.

\section{Results and Discussion}

Consistent with previous work [9], the $3 \mathrm{C}-\mathrm{SiC} \mathrm{p}^{+} \mathrm{n}$ junction diodes emitted yellow-green light observable with the naked eye under sufficient $(>2 \mathrm{~mA}$ ) forward bias. $\mathrm{C}-\mathrm{V}$ measurements revealed 
that the doping of the lighter-doped n-side of the junction systematically varied from $\sim 2 \times 10^{16} \mathrm{~cm}^{-3}$ on one side of the wafer to $\sim 5 \times 10^{17} \mathrm{~cm}^{-3}$ on the other, which was not unexpected for the growth reactor configuration that used un-coated graphite susceptor and no sample rotation.

The reverse $\mathrm{I}-\mathrm{V}$ behavior of devices spanning the measured

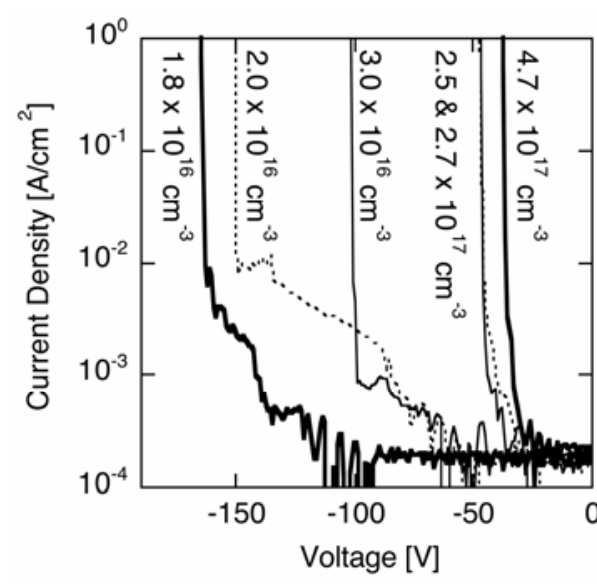

Fig. 2. Measured reverse I-V characteristics at $25{ }^{\circ} \mathrm{C}$ on six $3 \mathrm{C}-\mathrm{SiC} \mathrm{p}^{+} \mathrm{n}$ junction diodes with various n-layer dopings.

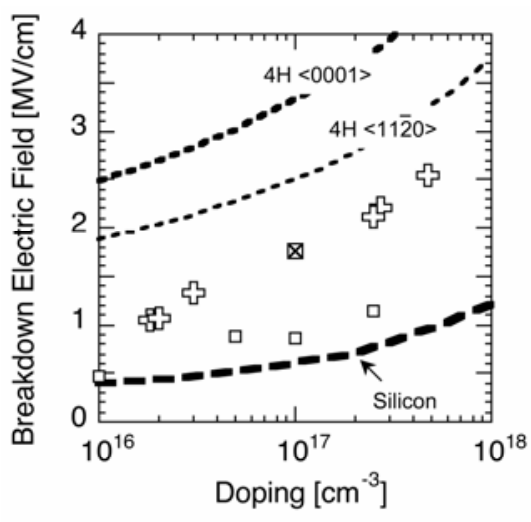

ङ $3 \mathrm{C}$ on Step-Free 4H (this work) $\square 3 \mathrm{C}$ on Silicon [13]

$\otimes 3 \mathrm{C}$ on $6 \mathrm{H}[9]$

Fig. 3. Breakdown electric field as a function of n-layer doping (see text). blocking-layer doping range is shown in Fig. 2. Excellent reverse-leakage behavior, below the measurement noise floor for the majority of the sweeps, was observed. It is worth noting that leakage current densities shown in Fig. 2 are significantly less than the previous lowest leakage for $3 \mathrm{C}-\mathrm{SiC} \mathrm{p}^{+} \mathrm{n}$ diodes of similar blocking voltage [9]. The reverse I-V curves of Fig. 2 also exhibit a sharp breakdown knee characterized by more than $50 \mathrm{X}$ current increase per volt at breakdown. The breakdown voltage did not degrade with multiple measurement sweeps with instrument current compliance limit set to 2 $\mathrm{A} / \mathrm{cm}^{2}$. As expected, the $3 \mathrm{C}-\mathrm{SiC} \mathrm{p}^{+} \mathrm{n}$ junction diode breakdown voltage increased as measured blocking layer doping decreased.

The peak electric field $\mathrm{E}_{\mathrm{B}}$ in each diode at breakdown can be estimated using the well-known procedure described in [10] with doping $\mathrm{N}_{\mathrm{A}}$ extracted from $\mathrm{C}-\mathrm{V}$ measurements and $\mathrm{I}-\mathrm{V}$ measured breakdown voltage knee $V_{B}$ apparent from Fig. 2. The hollow plus symbols plotted in Fig. 3 show the resulting breakdown field calculated for the six 3C-SiC devices as a function of measured blocking n-layer doping. For comparison, Fig. 3 also plots previously reported diode breakdown fields from $4 \mathrm{H}-\mathrm{SiC}[11,12]$, other previously reported $3 \mathrm{C}$ SiC samples [9,13], and silicon [10]. The Fig. 3 experimental results indicate that the breakdown field of n-type $3 \mathrm{C}$-SiC is at least twice the breakdown field of 2 silicon, but is only around half the breakdown field of $<0001>4 \mathrm{H}-\mathrm{SiC}$ for the doping range studied.

Fig. 4 shows the forward bias behavior of two devices both before (solid lines) and after (dashed lines) prolonged ( $>20$ hour) forward-bias stressing at $100 \mathrm{~A} / \mathrm{cm}^{2}$. For currents above $\sim 1 \mathrm{~A} / \mathrm{cm}^{2}$, the forward I-V characteristics before and after stressing are virtually identical. Interestingly, the stressing removed a low-current conduction hump evident in the $4.7 \times 10^{17} \mathrm{~cm}^{-3}$ pre-stress $\mathrm{I}-\mathrm{V}$. The saturation current density $\mathrm{J}_{0}$ and diode ideality factor $n>2$ (Fig. 4) are higher than might be expected for nominal 3C-SiC pn junction diodes. Because it is effectively in series with the $3 \mathrm{C} \mathrm{p}^{+} \mathrm{n}$ junction, it seems unlikely that the buried $3 \mathrm{C} / 4 \mathrm{H}$ heterojunction would cause diode current (i.e., $\mathrm{J}_{0}$ ) to increase. Lacking larger device

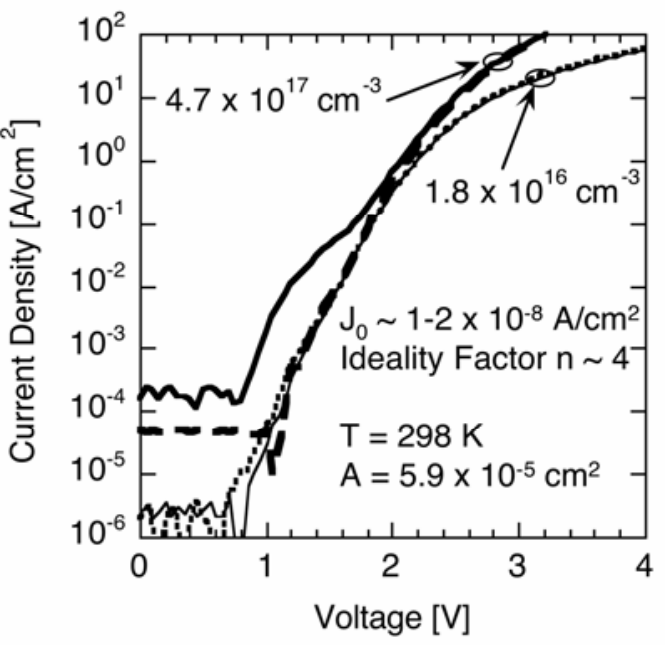

Fig. 4. Forward current vs. voltage plots of two $3 \mathrm{C}-\mathrm{SiC} \mathrm{p}^{+} \mathrm{n}$ diodes before (solid lines) and after (dashed lines) bias stressing at $100 \mathrm{~A} / \mathrm{cm}^{2}$. 
sizes to test perimeter-to-area leakage effects, we are left at this time to conjecture that perhaps some forward I-V non-idealities may arise from surface current effects around the etched diode periphery in these small-area (i.e., large perimeter-to-area ratio) devices.

Fig. 5 summarizes forward current bias stress tests conducted on four of the $3 \mathrm{C}^{+} \mathrm{n}$ diodes. In particular, Fig. 5 plots the applied forward voltage $V_{F}$ required to maintain $100 \mathrm{~A} / \mathrm{cm}^{2}$ current as a function of time. All devices tested were highly stable in that $\mathrm{V}_{\mathrm{F}}$ changed less than $50 \mathrm{mV}$ for all tests. Thus, these small-area $3 \mathrm{C}$ devices do not exhibit high forward current instability observed in 4H-SiC bipolar junction diodes [14]. However, no conclusions on relative stability of 3C-SiC versus $4 \mathrm{H}-\mathrm{SiC}$ against bipolar recombination enhanced degradation should yet be drawn from this very limited initial study of very small area $3 \mathrm{C}$ diodes with relatively low blocking voltage compared to degradation observed in large-area high blocking voltage $4 \mathrm{H}-\mathrm{SiC}$ diodes.

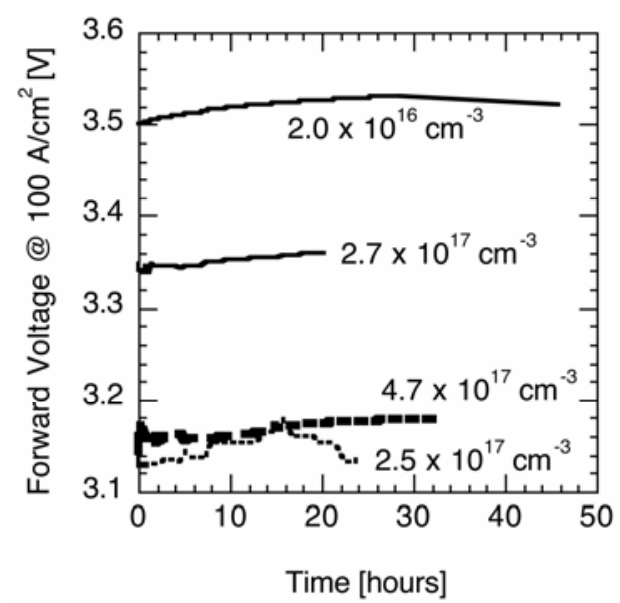

Fig. 5. Forward voltage required to maintain $100 \mathrm{~A} / \mathrm{cm}^{2}$ current flow versus stress time for four $3 \mathrm{C}-\mathrm{SiC} \mathrm{p}^{+} \mathrm{n}$ diodes with various blocking layer dopings.

\section{Summary}

The electrical performance of $3 \mathrm{C}-\mathrm{SiC}$ bipolar $\mathrm{p}^{+} \mathrm{n}$ junction diodes fabricated from high quality mesa heterofilms has been studied. For the $3 \mathrm{C}$-SiC polytype, the diodes exhibit state of the art low reverse leakage, high breakdown electric field, and stable forward voltage at high current density.

Acknowledgements: This work was funded and carried out under the Ultra Efficient Engine Technology Project at NASA Glenn Research Center. The authors thank G. Hunter, E. Benavage, R. Okojie, J. A. Powell, B. Osborn, M. Mrdenovich, G. Beheim, R. Meredith, T. Ferrier, D. Lukco, K. Laster, C. Blaha, P. Lampard, J. Gonzalez, D. Androjna, and L. Matus at NASA Glenn and Prof. M.-C. Cheng at Clarkson University for their support.

\section{References}

[1] J. Wan, et al.: IEEE Electron Device Lett. Vol. 23 (2002), p. 482.

[2] H. Nagasawa, et al.: in Silicon Carbide: Recent Major Advances, W. J. Choyke, H. Matsunami, and G. Pensl, Eds. (Springer-Verlag, Berlin 2003), p. 207.

[3] P. G. Neudeck and J. A. Powell: in Silicon Carbide: Recent Major Advances, W. J. Choyke, H. Matsunami, and G. Pensl, Eds. (Springer-Verlag, Berlin 2003), p. 179.

[4] Cree, Inc.: Durham, NC USA, http://www.cree.com.

[5] D. J. Larkin: Phys. Stat. Sol. A Vol. 202 (1997), p. 305.

[6] Aixtron Inc.: Model AIX 200/4 HT, http://www.aixtron.com.

[7] J. A. Powell, et al.: Appl. Phys. Lett. Vol. 59 (1991), p. 333.

[8] R. S. Okojie, et al.: J. Appl. Phys. Vol. 91 (2002), p. 6553.

[9] P. G. Neudeck, et al.: IEEE Trans. Electron Devices Vol. 41 (1994), p. 826.

[10] B. J. Baliga, Modern Power Devices, 1st ed. (Wiley \& Sons: New York, 1987), p. 67.

[11] A. O. Konstantinov, et. al.: Appl. Phys. Lett. Vol. 71 (1997), p. 90.

[12] S. Nakamura, et. al.: J. Appl. Phys. Vol. 80 (2002), p. 3355.

[13] C. W. Liu and J. C. Sturm: J. Appl. Phys. Vol. 82 (1997), p. 4558.

[14] S. Ha and J. P. Bergman: MRS Bulletin Vol. 30 (2005), p. 305. 